\title{
Physical Education Curricula and the Requirements of Progress in Technology and Electronics
}

\author{
Moustafa El Sayh Mohammed Ahmed*
}

\begin{abstract}
:
The development of physical education curricula should be based on the social, cultural and economic vision of the community, as well as changes introduced into the teaching strategies and the giant steps already taken in the field of information technology. This is particularly true in view of the methodology currently used in higher education and scientific research (in Egypt??), the rapid changes in the (demographic??) composition of the students and the effective collaboration of the different disciplines, aiming at promoting higher education from an e-learning perspective, to meet the ever-increasing demand on higher education.
\end{abstract}

\section{The Physical Education Curriculumul Development Process, Aims and Vision}

\section{Aim of the Development Process:}

Establishing sustainable systems to create the balance between practicing sport and individuals of all classes in the society.

What do we want from students in the light of new developments and the development of curricula?

As a result of the tremendous technological progress in all fields, it has become necessary to introduce changes in curricula and their organization, including:

On the intellectual, cognitive level:

- Graduates with the B.Sc degree should be:

- Well-educated citizens qualified to contribute a leader role in their society;

- Well aware of basic principles and knowledge in their field of specialization;

- Open-minded and with an international perspective;

- Thoughtful and critical;

- Able to contribute to solving problems in their field of specialization and to achieve the integration of knowledge;

- Able to explore sources of information;

* Professor, Faculty of Physical Education for Boys, Alexandria University, Egypt.
- Able to understand and follow up with scientific methods;

- Able to adapt, and should show flexibility in applying knowledge and skills, and be creative.

\section{On the skillful level:}

Graduates should possess the technical skills required for their field of specialization, be able to use electronic media effectively, and show efficiency in oral and written communication.

\section{On the value level:}

- Graduates should express commitment to continue life-long learning;

- Graduates should recognize their professional role;

- Graduates should move in harmony with different cultural environments;

- Graduate should show demonstrate a high degree of morality;

- Graduates should be able to work efficiently in a team work spirit.

\section{What we need to develop higher education curricula}

\section{We need to:}

- Build capacities not just transfer technology, in order to establish the appropriate research databases and stimulate creativity; 
- Build data bases as a means of cooperation between researchers working on similar subjects, both nationally and regionally;

- Encourage the public to invest in research and development;

- Utilize modern communication technologies and software in order to harness the power of knowledge and facilitate e-learning so that anyone can have access to the same knowledge anywhere and at any time. This is the only way to break through the current stand-still situation in higher education and help universities learn self-marketing.

\section{Means of application:}

These include:

- Promoting transfer through consultation and participation;

- Policies aiming at re-structuring value systems;

- Using the digital reform technology through:

- Building human capacities;

- Transferring institutional capacities;
- Re-structuring organizational an managerial capacities;

- Teaching multi-media: theory and practice, and securing programs at reasonable prices;

- Targeting students communities in remote areas.

\section{Factors of Success:}

To ensure the success of physical education curricula, there must be:

- A clear vision;

- Clearly defined strategy and goal

- Well-developed human resources (technical creativity);

- Coping with developments on the professional level;

- Responding to changes on the economic, agricultural, cultural and educational levels;

- A balance between theory and practice;

- Appropriate logistics (unrestricted access to computer-based educational technologies and the use of electronic mail) 